\title{
DIE F.A.K. EN DIE TOEKOMS
}

\section{Inleiding: Veertig Jaar gelede}

Waar die Federasie van Afrikaanse Kultuurvereniginge (FAK) vanjaar sy veertigste bestaansjaar gedenk, is dit seker gepas om hierdie beskeie toekomsblik te bind aan 'n rigtingbepalende terugblik. In die notule van die Uniale Taal- en Kultuurkonferensie wat op 18 en 19 Desember 1929 in Bloemfontein gehou is, lees ons: „Geesdriftige kultuurstryders hou krygsraad, krygsraad vir meer stelselmatige strydvoering... Leemetfordskote en konsentrasiekampe om die nasie te oorbluf. Daarna skynvrede en "peaceful penetration” om hom aan die slaap te sus. Dan die daad. Gaan daardie tragedie ook op Suid-Afrikaanse bodem volspeel word? Dit is ' $n$ vraag wat meer as een Boerehart beangstig, as hy sien hoe sy volk geleidelik ontaard, hoe die stroom van uitlandse kultuur alles oorweldig, hoe stuk vir stuk ons eie goed soos ou-ou oewerbome uitgeruk en meegesleur word, om later as dooie opdrifsels teen die walle uitgestoot te word..." Toe is daar besluit: „Nie met die klap van Mauserskote nie, nie met die kraak van bomme en kartetse nie, maar met die warm sonnegloring van ons Afrikaanse liefde en met die stille almag van ons Afrikaanse woord, gaan ons die stryd volstry". In hierdie verhewe moment is die FAK gebore, draer van ' $n$ verhewe gedagte, naamlik dic samesnoering van alle kragte van die Afrikanerdom, in 'n eenheid wat gewortel is in ons Christeliknasionale lewens- en wêreldbeskouing, die handhawing en bevordering van die Afrikaanse taal en die uitbouing en behartiging van alle Afrikaanse kultuurbelange, stoflik sowel as geestelik. Die ontstaan van die FAK was die uiting van 'n roering diep in die volksiel.

\section{Na veertig jaar}

Sedert sy stigting, 'n daad wat in ons volksverhaal reeds as ' $n$ betekenisvolle en historiese geleentheid bekend geword het, het die FAK, soos die bestendige noordoostewind, reën op baie terreine van die kultuurakker gebring en kan hy terugkyk op ,'n pad van stryd en swaarkry saam met die Afrikanervolk, maar ook 'n pad waarop die bakens ingeryg staan van die een klinkende kultuurdaad en oorwinning na 
die ander". (Die Volksblad - 21 Junie 1969.) Ek wil nie eers 'n opsomming probeer gee van wat die FAK reeds bereik het nie, maar gaan volstaan met die woorde van dr. D. F. Malherbe in 1954 by geleentheid van die silwerjubileum van die FAK: „As die volledige geskiedenis van die opkoms van die Afrikaanse taal en kultuur eenmaal geskrywe word, sal die FAK daarin een van die hoogste ereplekke verkry. Die vraag kan nou reeds gestel word: Waar sou ons volk vandag in daardie opsigte gestaan het as daardie organisasie daar nie was nie?' Vandag, na veertig jaar, is die FAK 'n magtige organisasie met 'n netwerk van skakelpunte oor die hele land: Enersyds is oor die 2,000 geaffilieerde en meewerkende liggame tans by die FAK ingeskakel, en as in gedagte gehou word dat elkeen van hierdie liggame 'n gemeenskap op die een of ander wyse dien, kan enigsins 'n idee gevorm word van die moontlike trefkrag van die FAK. Andersyds spreek die FAK regstreeks tot die individuele Afrikaner deur die doelbewuste inskakeling van donateurlede en lewenslange lede waarvan daar tans plusminus 10,000 is. Hieruit blyk duidelik dat die trefwydte van die FAK as kultuurspreekbuis groot is, maar andersyds is dit dringend noodsaaklik dat op die kultuurterrein, deur 'n diepe begrip en dinamiese optrede, op die prinsipiële grondslag van die verlede, die kulturele eise van ons tyd die hoof gebied moet word, selfs al gaan dit gepaard met striemende selfondersoek en groot opoffering. In hierdie gees wil ek kortliks die lig laat val op die toekomstaak van die FAK.

\section{Die F.A.K. en die toekoms}

\section{a) Die positiveringstaak van die $F A K$}

Die FAK is nie 'n bloot koördinerende liggaam nie en sy taak is nie oppervlakkig organisatories en administratief van aard nie.

Die geestesklimaat waaruit die FAK gegroei en ontstaan het, het kultuur gesien as 'n bepaalde wyse van lewensindiensstelling ooreenkomstig spesifiek Calvinistiese lewenswaardes, gegrond op die Woord van God. „Hierdie lewenswaardes, wesenswaarhede, tydlose beginsels, algemene riglyne moet gekonkretiseer en uitgewerk word tot pregnante leef- en gedragreëls vir die konkrete samelewingsituasies". Die positiveringstaak van die FAK lê in die oplegging en inskerping van hierdie 
positiewe norme in die kulturele lewe van die Afrikaner, „sodat dit aanvaar word as navolgenswaardige leefreëls", met ander woorde die daarstelling op kulturele gebied van 'n waardemeter vir die beoordeling van wat geld en van wat behoort te geld. Hierdie positiveringstaak is die geestelike lanseerbasis, die ontbrandingspunt van 'n kultuuraktiwiteit wat moet lei tot die vorming van 'n kultuurpatroon, ooreenkomstig „die deur God bepaalde kultuur-ordinansies en kultuurnorme, hoe ook al die eie-aard van die mens sy stempel op die kultuur afdruk". (H. G. Stoker - Stryd om die Ordes.) Hierdie ontbrandingspunt lê vir die Christen-Afrikaner op die snypunt van die vertikale lyn (die geloofsverhouding van die mens tot God) en die horisontale lyn (die verhouding van mens tot mens), die oorspronklike kultuuropdrag om die aarde te onderwerp, soos Stoker dit stel: „God het die mens, die kultuurvormer, as heer geplaas oor Sy skepping. Die mens heers kultuurvormend oor alles wat God aan sy sorg toevertrou het. Hierdie heerwees, hierdie heer-skappy, hierdie heersing en beheersing druk die menslike heer-likheid op aarde uit". Maar hierdie onderwerping van die aarde mag nie 'n doel op sigself wees nie, maar moet strek tot eer van God „uit wie en tot wie alle dinge is". Die positiveringstaak van die FAK lê dus in die inprenting, die inskerping, die inweef van hierdie tydlose riglyn in die kultuurpatroon van ons volk.

\section{b) Lewensbeskoulike volksbou}

„Ooreenkomstig sy Christelik-nasionale grondslag moet die FAK kultuurvormende en kultuurhervormende werk verrig; hierdie volksliggaam moet bewus volksvormend en kultuurkerstenend optree en daardeur ' $n$ bydrae lewer tot die suiwere kerk- en volksverhouding. Dit is nie die taak van die FAK om die kerkbegrip suiwer te stel nie (dit moet in die Woordbediening en in die kerkvergadering geskied), maar as volksorganisasie en -instrument, as spreekbuis en diensmiddel van 'n andersoortige lewensvorm, die volk, is hy aangewese om hom toe te lê op die volksbegrip. Hy stel hom dus dienend ten doel om die Afrikanervolk soveel moontlik te laat beantwoord aan die ideaal van 'n Christelike volk. En as hy kan meehelp dat die Afrikanervolk in sy wese Christelik bly 
en al meer word, sal hy daarmee een van die mees fundamentele verhoudingsprinsipes stimuleer en bestendig".

„Enersyds hou hierdie taak in die positiewe uitbouing van die Christelik-nasionale lewensbeskouing, nie 'n kerkistiese benepe lewensbeskouing of 'n Roomsgetinte verkerkliking nie, maar ' $n$ belydeniskragtige en besielende dryfveer wat berus op 'n sisteem van Christelike beginsels vir al die volksakkers, 'n sisteem wat sinvolle differensiasie huisves en voortdurend ontplooiend verwerklik kan word. Dit is dus 'n grootse beskawingstaak wat hier nooit die volmaaktheid kan bereik nie, altyd taakstellend, nooit frustrerend en stagnerend nie."

Andersyds hou hierdie taak in 'n voortdurende waaksaamheid, ' $n$ geestelike paraatheid teen die gevare wat ons lewensbeskouing bedreig, ' $n$ weerbaarmaking van hulle wat daagliks staande moet bly teen die aanslae van die Humanisme, die Liberalisme, die Kommunisme, die Materialisme en die volslae Ateïsme. Die aanvalstegnieke van hierdie vyandige magte is subtiel-berekend, aftakelend en ondergrawend. Ek noem slegs 'n paar: gesagsverwerping onder die voorwendsel dat gesagshandhawing indruis teen die vrye selfbeskikkingsreg van die individu, ' $n$ afkeer van staatsbemoeiing en staatsingryping deur wetgewing ten opsigte van byvoorbeeld lektuur, rolprente, Sabbatheiliging, openbare sedelikheid, 'n valse verdraagsaamheid, 'n gerasionaliseerde sedeleer waarvolgens nie die Skrif normatief is nie, maar die konsensus van die smaak en opinies van mense, vrye liefde met miskenning van die heiligheid van die huwelik en 'n algemene broederskapsleer, die opvoeding en wetenskapsbeoefening sonder binding aan die beginsels van die Bybel, die beoefening van die kuns om die kuns, sonder eerbiediging van die sedewet.

Kortom: Die toekomstaak van die FAK staan duidelik en ondubbelsinnig in die teken van die lewensbeskoulike stryd, weerbaarmakend, verdedigend, maar as dit nodig is, ook vreesloos aanvallend.

\section{c) Die behoud van die identiteit van die Afrikaner}

Sonder om hom op die partypolitieke terrein te begewe het die FAK as volkspolitieke organisasie in die proses van samewerking tussen die kultuurgroepe op staatkundige gebied 'n verantwoordelike toekomstaak. Die Nasionale Party stel 
hom ten doel „om 'n kragtige besef van nasionale selfstandigheid verder te ontwikkel, sowel as 'n sterk gevoel van nasionale eenheid, gegrond op: die gemeenskaplike en onverdeelde trou en toewyding aan die Republiek van Suid-Afrika en sy belange; op onderlinge vertroue en op die beskerming van die gelyke regte van beide Afrikaans- en Engelssprekendes en die wedersydse waardering van elkeen se kulturele bydraes". Hierdie samewerking moet egter gepaard gaan met die behoud van die eie identiteit van elke groep en sonder prysgawe van beginsels. Dit het die huidige Eerste Minister herhaaldelik en onomwonde beklemtoon: „Ek hoef niks in te boet om met die ander saam te werk nie... My samewerking met iemand wat Engelssprekend is, kan onder geen omstandighede daartoe lei dat ek of my beleid versaak, of my beginsels verwater of dat ek die gevaar loop om my identiteit te verloor nie". Voorts het hy elke kultuurgroep daarop gewys dat dit sy plig is om sy volkseie kultuur uit te bou. Suid-Afrikanerskap, 'n landsgebondenheid, sluit dus nie Afrikanerskap, 'n volksgebondenheid, uit nie; inteendeel dit veronderstel en beklemtoon dit.

In hierdie strewe om die behoud van 'n eie identiteit mag een kernwaarheid egter nie vergeet word nie. Prof. B. F. Nel stel dit soos volg: „Onder sulke omstandighede tree 'n kultuur-psigologiese wet na vore wat keer op keer in die geskiedenis hom laat geld het, naamlik dat waar 'n sterker meer verbreide kultuur op dieselfde bodem, binne dieselfde staatkundige gebied moet ontwikkel, die sterker kultuur sy stempel afdruk op die jonger kultuur en selfs dreig om die jonger kultuur heeltemal te ontaard".

Waar die FAK by geleentheid van die volkstemming oor Republiekwording nie afsydig gestaan het nie, maar ondubbelsinnig verkondig het ,dat dit in belang van ons kultuurtoekoms is dat die Republiek ook deur die toedoen van elke kultuurgenoot tot stand gebring word", daar is hy vasbeslote om ,hom ook in die toekoms in die diens van die Afrikanerdom te beywer en te waak oor mooi besittinge van die gees wat ons ouers en voorouers, dikwels met moeite en verdriet, aan 'n onherbergsame land ontworstel het... ons sal dit doen met ál die kragte en al die middele waaroor ons beskik, al is daar ook nóg soveel wat ons van politiek beskuldig" (prof. dr. H. B. Thom). Die FAK was mede-skepper van die 
Republiek, maar moet ook mede-bouer bly.

In dié bouproses is dit die taak van die FAK om te help dat die rugare-drade van ons tradisionele erfenis stewig ingeweef bly in ons staatkundige patroon, dat ons volksgenote roepingsbewus as 'n selfstandige kultuurgroep behou en gebou word in 'n hegte eenheid wat gewortel is in ons lewensen wêreldbeskouing, dat binne die raamwerk van goeie SuidAfrikanerskap (liefde vir 'n bepaalde land, trou aan 'n bepaalde staat, d.w.s. 'n landsgebondenheid) ware Afrikanerskap ('n gevoel en 'n wil wat gerig is op 'n innige verbondenheid met 'n groep mense wat 'n volk vorm, die Afrikanervolk) altyd en eerbaar sal gedy.

Wanneer die FAK optree as kampvegter vir die behoud van die identiteit van die Afrikaner in ons staatkundige patroon, verleen hy volle erkenning aan die Nasionale Party as die politieke bolwerk van die Afrikaner, en, soos in die verlede, aanvaar hy dat ons politieke leiers ook kultuurleiers moet wees, beklemtoon hy dat hierdie onderskeiding geensins dui op 'n skeiding tussen politiek en kultuur nie, maar dat dit die bevestiging is van 'n standpunt wat reeds baie jare (en vandag nog) deur ons volksleiers gehuldig word.

\section{Masjinerie}

Hierdie drieledige taak (positivering, lewensbeskoulike volksbou en handhawing van die identiteit van die Afrikaner) kan alleen doeltreffend verrig word, indien die nodige masjinerie daarvoor geskep en beskikbaar gestel word.

a) Meewerkende en geaffilieerde liggame

Hiervoor is in die eerste plek die medewerking van ons drie Afrikaanse kerke 'n lewensbelangrike vereiste. Godsdiens is nie kultuur nie, maar die Christelik-Calvinistiese kultuuropvatting berus op 'n noue verband tussen godsdiens en kultuur. Wanneer kultuur as die vervulling van 'n goddelike opdrag beskou word, dien die mens God daarmee. Die kerk bly dus verantwoordelik vir die instandhouding van die vertikale lyn. Tweedens is die samewerking van ander landwye kultuurorganisasies op hoofbestuursvlak noodsaaklik - die Afrikaner beskik oor 'n aantal goed georganiseerde kultuurorganisasies binne beroepsgroepe (ATKV, AKPOL, AKVV, ATKB), besinningsorganisasies (Federasie van Rapportryers- 
korpse en VCHO, Instituut vir die bevordering van Calvinisme), diensorganisasies (Noodhulpliga en Vryburgers) en Jeugorganisasies (ASB, Federasie van Junior Rapportryerkorpse, Voortrekkers, Genootskap vir Volkskunde en Volkstaal) en Vroue-organisasies, ensovoorts, wat, sonder om enigsins outonomie of identiteit in te boet, in hul positiveringsaksie in 'n bruisende kultuurstroom gekanaliseer kan word. Derdens moet elke kontak- of skakelpunt in die land betrek word deur middel van regstreekse affiliasie of affiliasie deur plaaslike kultuurrade of gebiedskultuurrade: Kultuur is nie 'n elektriese gloeilamp wat brand, omdat hy by 'n groot sentrale kragstasie ingeskakel is nie, maar is 'n kaggelvuur wat plaaslik aan die brand gehou moet word; daarom is dit belangrik dat elke kultuurvereniging, feeskomitee, studiekring, ensovoorts, wat die grondwet van die FAK kan onderskryf, as skakelpunt dien vir hierdie positiveringsproses. Laastens moet elke reggesinde Afrikaner se samewerking verkry word as lid van die FAK, sodat die kultuurdraad deur middel van Handhaaf en ander publikasies in die huise en die harte van ons mense ingeweef word. Op hierdie wyse kan 'n kultuur-betonbouwerk opgerig word waarop kultuurorganisasies stewig kan voortbou.

\section{b) Algemene Vergadering}

Die jaarlikse Algemene Vergadering, die hoogste gesagsliggaam van die FAK, moet, soos in die verlede, dien as ' $n$ verteenwoordigende volksvergadering, waar besin word oor volksvraagstukke, besluit word oor toekomstake, standpunte van die Afrikaner geformuleer word en die vyande van ons volk geïdentifiseer word. Hierdie byeenkomste moet benut word as openhartige volksgesprekke, as lanseerbasisse vir besielde volkstake.

\section{c) Die Afrikaanse Nasionale Kultuurraad}

Die ANK waarin verteenwoordigers van die Afrikaanse kerke en landwye kultuurorganisasies dien, vergader minstens twee maal per jaar as koördinerende liggaam ten einde oorbodige en skadelike oorvleueling van werksaamhede deur oorlegpleging uit te skakel en onderlinge steun ten opsigte van kulturele aktiwiteite te bewerkstellig. Eendragtige optrede 
deur Afrikanerorganisasies is ' $n$ ideaal wat op hierdie wyse verwesenlik kan word.

\section{d) Die Uitvoerende Komitee van die FAK}

Naas die Algemene Vergadering, die hoogste gesagsliggaam van die FAK, voer hierdie komitee opdragte van die Algemene Vergadering uit en gee leiding en voorligting deur middel van omsendbriewe, publikasies, briefwisseling op hoë vlak, persoonlike optrede, onderhoude en onderhandelinge. Die notules van die Uitvoerende Komitee oor die afgelope 40 jaar is die verhaal van die een klinkende kultuurraad na die ander wat vir die Afrikaner deur sy gekose kultuurleiers aangepak en deurgevoer is. Die voorsitter van die Uitvoerende Komitee (en daar was slegs drie sedert die stigting van die FAK!) moet allerweë erken word as die kulturele leier van die volk.

\section{e) Nasionale Jeugraad van die FAK}

Die taak van hierdie raad is om die Afrikanerjeug te aktiveer tot doelgerigte optrede ter versekering van die voortbestaan en uitbouing van sy Afrikanerskap en Afrikanerkultuur, om die kultuuraksie van Afrikaanse jeugorganisasies te koördineer, jeugleierskursusse aan te bied en jeugkongresse te reël waar Afrikaanse jeugorganisasies gesamentlik kan besin en beplan ten opsigte van die kultuurtaak van die jeug. Hier lê miskien die deurslaggewende toekomstaak vir die FAK, want die jeug van vandag is die volk van môre.

\section{f) Musiekkommissie}

Hierdie kommissie oefen reeds 'n rigtinggewende invloed op die Afrikaanse musiek en sang uit en word tans allerweë as die amptelike liggaam en mondstuk vir die Afrikaanse musiek aanvaar. Waar volksmusiek so 'n belangrike deel van die volkskultuur vorm, sal hierdie belangrike werk met nougesetheid voortgesit moet word.

\section{g) Die Geskiedeniskomitee van die FAK}

Hierdie komitee beywer hom vir die bevordering van geskiedenis as skoolvak, die aankweek van liefde vir en kennis van ons vaderlandse geskiedenis en die sinvolle viering van 
ons volksfeeste. As daar gelet word op die kwynende belangstelling in Geskiedenis as skoolvak, die gebrekkige kennis van ons vaderlandse geskiedenis deur baie van ons volksgenote en die subtiele devaluasie en geringskatting van die eie volksgeskiedenis om koersloosheid te saai, kan begryp word dat hierdie komitee 'n sleutelrol sal speel in die toekomstaak van die FAK.

\section{h) Ekonomiese Kommissie}

'n Vaste Ekonomiese Kommissie is saamgestel met die oog op die ekonomiese bewusmaking en houding van die Afrikaner, navorsing op ekonomiese gebied en voorligting met betrekking tot ekonomiese aangeleenthede van ons volk. Waar die ekonomiese stryd en kultuurlewe van die Afrikaner nog altyd hand aan hand geloop het, sal daar 'n groot verantwoordelikheid op hierdie komitee rus.

\section{i) Taal- en Taalhandhawingskomitee}

Taalhandhawing en -bevordering bly steeds een van die belangrikste take van die FAK. Wat die vordering van ons taal betref, het ons beslis stof tot dankbaarheid, maar geensins rede tot tevredenheid nie. „Waar twee kulture saamleef, eindig die taalstryd nooit!"

Benewens sy koördinerende en samesnoerende funksie is die FAK dus bedoel om ' $n$ histories- en prinsipieel-gefundeerde volksorganisasie te wees wat, volgens 'n vasgestelde en besielende lewensbeskoulike patroon, 'n erkende plek verower het as kerk-volk-skakel en as staat-volk-skakel op die hoogste vlak. In sy organisatoriese opset beskik hy oor 'n hand wat die kulturele dag van ons tyd in al sy weelde kan pluk, 'n hand wat draai om die lewegewende pols van ons lewens- en wêreldbeskouing waardeur die lewensbloed vloei na die vyf vingers van 'n eie opvoeding, 'n eie geskiedenis, 'n eie kuns, 'n eie ekonomie en 'n eie taal. Voeg nog hierby die unieke feit dat in sy Uitvoerende Komitee en onder-komitees die voorste kultuurleiers, geestelike en politieke leiers, akademici, musici, historici, taalkundiges en ekonome, deskundiges van wêreldformaat, gedien het en steeds dien, en jy kan 'n beeld vorm van die potensiële slaan- en trefkrag van hierdie hand. Die keur van die breinkrag en geeskrag van 'n volk is hier be- 
reid om, sonder vergoeding, hul kennis en krag tot beskikking van hul volk te stel - die kulturele denkbron en diensmiddel van die Afrikaner wat as hy aan sy doel beantwoord, ' $n$ klein volk groot kan maak, groot in sy kerstenende en beskawende taak in 'n donker land, groot in sy stewige stand teen 'n verwarde en verwarrende wêreld, maar veral groot in sy ootmoed voor die God uit wie, deur wie en tot wie alle dinge is.

Daarom, soos ' $n$ banier op ' $n$ kaal berg, die hoogste strewe van die FAK in die woorde van N. P. van Wyk Louw:

Dat ons nie gebreek sal word

soos hul geweld dit wou,

maar dat ons hoog sal lewe,

net aan God en aan ons volk getrou.

Trou alleen aan die hoogste wat ons ken,

meer nog as aan vriend of broer,

dat ons die Kosbare en Edele,

veilig deur die skare dra.

D. J. Viljoen.

Johannesburg.

Vir die opstel van hierdie referaat is die volgende geraadpleeg:

Dr. J. J. de Klerk: Die Positiveringstaak van die Gereformeerde Kerkinstituut.

Dr. D. D. Rosslee: Die Verhouding Kerk en Volk vereis Christelike Volksbou. 